\title{
Correlation coefficients between retinal lesions and visual acuity in diabetic retinopthay
}

\author{
J. PRiGe, H. H. STAUfFER, W. D. HOGAN, AND J. H. LAWRENGE
}

From the Donner Laboratory, Group in Medicine and Biology, Lawrence Radiation Laboratory, University of California, Berkeley, California, U.S.A.

Diabetic retinopathy has become a major cause of blindness among the technologically advanced nations. For therapeutic evaluations, the natural history of this disease should be considered as a stochastic process if an adequate and useful probability model is to be developed. A definite interval of time passes, in most instances, from the onset of diabetes mellitus to the appearance of ophthalmic manifestations. Typically, this latent period is followed first by a period of mild retinopathy and then by a proliferative phase during which the predominant visual loss occurs, and after this by a quiescent period in which further visual deterioration may proceed from slow extension of the retinal disease, secondary glaucoma, cataract, and so forth (Beetham, 1963; Caird and Garrett, r963; Dobree, 1969).

The duration of the latent period and possibly also that of mild retinopathy is difficult to establish in patients whose diabetes has developed during adult life, but among those whose disease is discovered in or just after childhood a fairly well demarcated time of onset can generally be established (Frydman, Delcher, Tierney, and Shipp, 1963; Dollfus and Haye, 1957). The latter group would be best for the construction of a duration-severity or progression model. After the appearance of the retinopathy and into the quiescent phase, either group may be adequate for study.

The retinae of patients with diabetic retinopathy have an enormous information content and this requires the handling of an unwieldy amount of data. Simplification of a protocol for studying this problem could be achieved by selecting a representative lesion from groups that correlate with each other and by omitting those lesions which have a minimal effect on vision. This paper is directed towards examining the correlations among lesions in the proliferative phase and their influence on the visual outcome.

\section{Materials and methods}

Data were coded from serial fundus photographs (Kodachrome transparencies) comprising a retinal composite of ten per eye. These were taken annually or semi-annually on $\mathbf{1}_{2} 2$ patients during an average period of 3 to 4 years after they had received pituitary irradiation with high-energy alpha particles at the Lawrence Radiation Laboratory's synchrocyclotron. The period of follow-up ranged from less than I to more than 8 years. When coded, the information was processed, using standard techniques for correlation coefficients, on a Control Data Corporation computer at the Lawrence Radiation Laboratory. An extensive programme for the evaluation of the multiple variables in this disease has been devised (Hogan and others, in preparation). 
The patients evaluated in this study represent a group with advanced retinopathy, since acceptance $\frac{\widetilde{J}}{3}$ for therapy was based on at least one haemorrhagic episode, progressive neovascularization, oro connective tissue proliferation. Retinal pathology was coded using an arbitrary scale on which $\vec{F}$ increasing severity was indicated by the highest score. Visual acuity is represented by a scale from o to 10 with the highest score equal to $20 / 30$ or $20 / 15$ and the lowest to no perception of light. A negative correlation between a fundus lesion and the visual scale indicates reduced vision and $\overline{\bar{N}}$ an advanced stage of that specific lesion.

The smallesi number of data points used in computing any correlation coefficients among the funduso lesions is 540 , and that between fundus lesions and visual acuity is 400 . Each point represents the information present on the ten composite slides so that altogether over ro,ooo slides were coded. L.esions were termed peripheral if beyond the macula, and central if inside it. If confluent with the $\vec{\omega}$ disc, they were coded as being present on it. In our terminology, connective tissue proliferation is indicated as proliferative retinopathy. The right and left eyes are considered as separate groups.

\section{Results}

The Figure shows the plus to minus range of correlations for retinal lesions and visualo acuity from the right and left eyes respectively. The symbols used to designate increasing $\vec{c}_{c}$ or decreasing correlation are explained in the key. The fundus lesions, listed at the side, are identified by letters which are the same for the rows and columns of the triangularo section. Correlations between fundus lesions can be found at the intersection of rows and columns. The single row at the bottom gives the correlation between visual acuity and $a \vec{\ominus}$ specific lesion, which is indicated by the letter above it.

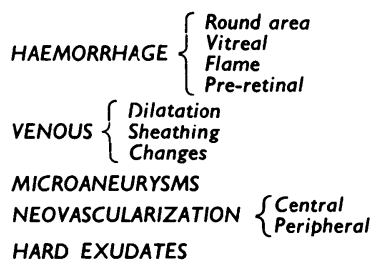

HARD EXUDATES

FIBROUS
PROLIFERATION $\left\{\begin{array}{l}\text { Central, flat } \\ \text { Central, vitreal } \\ \text { Peripheral, flat } \\ \text { Peripheral, vitreal }\end{array}\right.$
NEOVASCULARIZATION, Disc
FIBROUS PROLIFERATION, DisC
PHOTO QUALITY
HAEMORRHAGES, Round, number
VISUAL ACUITY

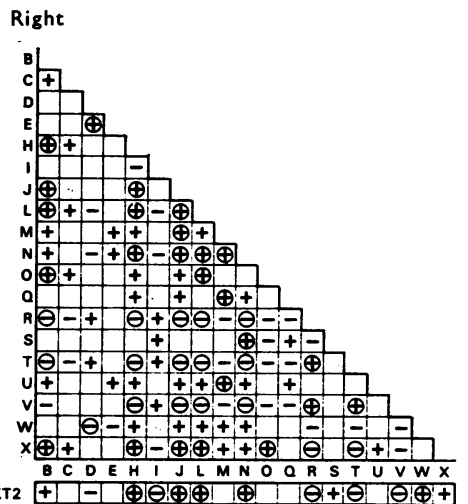

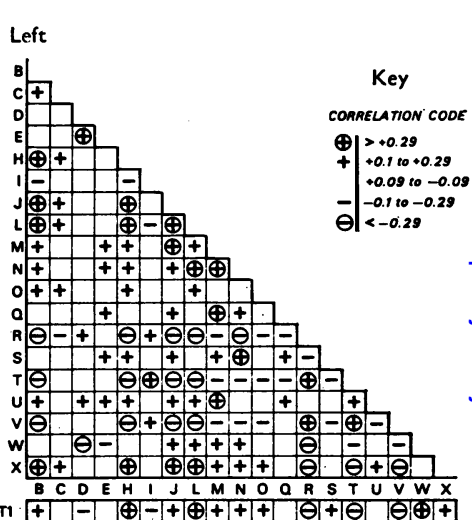

Two groups of retinal lesions can be separated by using this system. One consists of earlier lesions, such as venous distension, microaneurysms, and round haemorrhages, and ${ }^{\circ}$ the other of later lesions, represented by venous sheathing and proliferation into the $\mathcal{N}^{N}$ vitreous. The early lesions (letters $\mathrm{B}, \mathrm{H}, \mathrm{L}$, and $\mathrm{X}$ ) can be seen to correlate positively with visual acuity. Conversely, proliferation into the vitreous (letters $\mathrm{R}, \mathrm{T}$, and $\mathrm{V}$ ) has a strong negative correlation with visual acuity, indicating a deterioration of eyesight.

The clinical impression that flat islands of connective tissue (letters $Q$ and $\mathrm{S}$ ) appear $\stackrel{\oplus}{+}$ over pre-existing neovascularization (letter $\mathbf{N}$ ) is supported by the positive correlations between these lesions. Their effect on vision is minimal, as is shown by the plus under $\mathrm{S}_{\mathbb{\mathrm { D }}}^{\mathrm{O}}$ in the visual acuity row.

The Table lists the numerical values of the correlations, from strongly positive to stronglyọ negative, which exist between visual acuity and certain fundus lesions. It is evident that 
those lesions which on the Figure can be seen to correlate positively with each other correlate to approximately the same extent with visual acuity. Vitreal haemorrhage should have a more adverse effect on vision than appears to be the case, since severe haemorrhagic episodes are not represented in the slides and only the mildest vitreal haemorrhages were photographed.

Table Correlation of fundus lesions with visual acuity

\begin{tabular}{|c|c|c|c|}
\hline \multicolumn{2}{|l|}{ Eye } & Right & Left \\
\hline \multicolumn{2}{|l|}{ Venous dilatation } & $0 \cdot 5^{2}$ & $0 \cdot 45$ \\
\hline \multicolumn{2}{|l|}{ Microaneurysms } & $0 \cdot 50$ & 0.43 \\
\hline \multicolumn{2}{|l|}{ Neovascularization, peripheral } & $0 \cdot 26$ & $0 \cdot 4^{2}$ \\
\hline \multicolumn{2}{|l|}{ Venous changes } & $0 \cdot 28$ & $0 \cdot 31$ \\
\hline \multicolumn{2}{|l|}{ Round haemorrhages (area) } & $\overline{0 \cdot 28}$ & $0 \cdot 26$ \\
\hline \multicolumn{2}{|l|}{ Vitreal haemorrhages } & $-0 \cdot 22$ & $-0 \cdot 19$ \\
\hline \multicolumn{2}{|l|}{ Venous sheathing } & $\overline{-0.29}$ & $-0 \cdot 31$ \\
\hline \multirow[t]{3}{*}{ Vitreal fibrous proliferation } & Peripheral & $\overline{-0.56}$ & -0.47 \\
\hline & Disc & $\overline{-0.62}$ & $-0 \cdot 54$ \\
\hline & Central & $\overline{-0 \cdot 66}$ & $-0 \cdot 55$ \\
\hline
\end{tabular}

These represent the most positive and negative correlations

\section{Discussion}

Individual cases are at times observed in which the stage of retinopathy does not agree with the existing vision. Rather advanced retinal pathology is seen and yet the patient may maintain his vision for a considerable period of time (Babel and Rilliet, 1958; Fischer, I96 I ; Beetham, I963). This variability, important in the individual case, will not affect the statistical handling of such information from a sizeable number of patients. The Figure indicates that, when a population is examined, the progression of retinopathy will be accompanied by the expected visual deterioration for the group as a whole. A specific example of this is that of proliferative retinopathy extending into the vitreous. Certain lesions such as pre-retinal haemorrhages do not usually affect central vision directly and yet are ominous signs that later lesions (vitreal haemorrhage and connective tissue proliferation) will follow. Findings such as this emphasize the fact that the natural history of diabetic retinopathy must be considered as a stochastic process and that static handling of the data can be misleading.

Frequently the stage of retinopathy is quite different in the two eyes of the same patient, or if identical when selected for study may progress at a different rate. Patz and Berkow ( 1969) have shown that the prognosis for maintaining vision in the second eye is poor if one eye has suffered severe visual loss. For this reason, the right and left eyes are considered separately in this report. Though individual variation was often present, when considered as a single population our patients showed little difference between the right and left eyes. This suggests that alternate-eye studies should be useful in evaluating therapeutic approaches to diabetic retinopathy. 
The degree of correlation between fundus lesions is to a large extent time-dependent. An analysis of the kind reported here cannot demonstrate this. An example is the appear- 음 ance of fibrous proliferation from pre-existing neovascularization at the optic disc (Dobree, $\underset{\vec{\rho}}{\vec{\rho}}$ 1964). In the Figure a slight negative correlation between these two lesions is found for one eye and no evident correlation for the other, even though clinical impressions and other methods of analysis show this relation. In general, earlier lesions decrease or are masked as more advanced lesions increase. The changes which these retinal lesions undergo with time will be the subject of another report.

\section{Summary}

Correlation coefficients were examined between retinal lesions and visual acuity in $\frac{0}{0}$. patients with diabetic retinopathy. Standard statistical methods were used and a com- or puter programme has been devised. Certain retinal lesions can be grouped, so that a reduction may be possible in the number of variables needed to evaluate this disease. 공 A good correlation exists between extensive proliferative retinopathy and reduced visual 을 acuity. Isolated flat areas of proliferative retinopathy have little effect on vision.

\section{Bibliography}

BABEL, J., and RILLIET, B. (1958) Ophthalmologica (Basel), 135, $47 \mathrm{I}$

BEETHAM, W. P. (1963) Brit. F. Ophthal., 47, 6 I I

CAIRD, F. I., and GARRETT, c. J. (1963) Diabetes, 12, 389

DOBREE, J. H. (1964) Trans. ophthal. Soc. U.K., 84, 521

- (1969) "Symposium on the Treatment of Diabetic Retinopathy, Warrenton, Virginia, I968”, ed. M. F. Goldberg and S. L. Fine, p. 55. U.S. Public Health Service Publication No. 189o. Government Printing House, Washington, D.C.

DOLlfus, M. A., and HAYE, C. (1957) Bull. Soc. belge Ophtal., no. I I 5, p. I84

FisGher, F. (196r) v. Graefes Arch. Ophthal., 163, 397

FRYDMAN, J. E., DELGHER, H. K., TIERNEY, J. P., and SHIPP, J. c. (1967) Sth. med. J., 6o, 466

PATZ, A., and BERKow, J. W. (1969) "Symposium on the Treatment of Diabetic Retinopathy, Warrenton, Virginia, I968”, ed. M. F. Goldberg and S. L. Fine, p. 87. U.S. Public Health Service Publication No. I89o. Government Printing House, Washington, D.C. 